\title{
Study of Overhead Power Line Corridors on the Territory of Pskov Region (Russia) Based on Satellite Sounding Data
}

\author{
Sergei Mikhalap \\ Botany and Plant Ecology Department \\ Pskov State University \\ Pskov, Russia \\ sgmikhalap@gmail.com
}

\author{
Sergei Trashchenkov \\ Electrical Power Engeneering Depart- \\ ment \\ Pskov State University \\ Pskov, Russia \\ trashchenkov@gmail.com
}

\author{
Vera Vasilyeva \\ Geokvantum \\ Children's technopark "Quantorium" \\ Pskov, Russia \\ rveravas@gmail.com
}

\begin{abstract}
Overhead power lines (OPL) form the basis of a power grid. Reliable energy supply depends on no-failure operation of these long-length elements of energy infrastructure. More than $12,000 \mathrm{~km}$ out of $45,000 \mathrm{~km}$ of OPL in Pskov region (Russia) pass through forests. This study investigates the possibilities of using satellite-sensing data to assess the conditions of corridors for OPL with different voltage levels. Authors evaluated compliance of actual data with requirements of national standards. The dynamics of vegetation and local topography based on synthetic aperture radar data and multispectral images were taken into account.
\end{abstract}

Keywords-GIS, NDVI, overhead power lines, satellite sounding data.

\section{INTRODUCTION}

Safety and reliability of power transmission systems is an important issue for countries with extensive territory such as Russia. Maintaining the grid infrastructure in proper condition requires various types of monitoring based on different technologies. Legwork with overhead power lines (OPL) as a way of monitoring is still used in many cases, but the economic feasibility of the use of remote monitoring technology becomes more and more obvious.

There are wide range of studies dedicated for different methods and different purposes of OPL remote monitoring. Quite comprehensive review of remote monitoring technologies for OPL contains in [1]. Authors described ways of information acquisition for monitoring of both OPL components and vegetation around them. They discussed satellite and aerial images, laser scanning technology. Many studies are focused on OPL components. Paper [2] describes monitoring system with capacitive sensors for detecting ice accretion on OPL. Such monitoring allows to prevent ice overweight wire breakage. Monitoring of pylon's structural strength is a topic of studies [3], [4]. These studies explore sensors systems and methods of processing obtained data to examine condition of power transmission line poles. Another important components of OPL are insulators. Paper [5] contains feasibility analysis of implementation of RF antenna for online monitoring of outdoor insulators. Partial discharges caused by surface pollution can be negative factor that leads to failure. Surface pollution of insulation as an important factor for monitoring also is described in [6]. Authors measured surface leakage current of disc insulator in laboratory environment.

OPL are spread over large territories with different landscapes and environment. Environmental remote monitoring of OPL is another area for numerous studies. Monitoring of wind speed by fiber Bragg grating anemometer is a topic of [7]. This anemometer does not require power supply for work and is able to transmit signal through optical fiber composite overhead ground wire. Interplay of OPL and bird is described in [8]. Bird strike indicator as a device on wire that allows to get information about bird strikes is a topic of the report [9]. OPL corridors is another area for monitoring. In [10] multispectral satellite stereo images uses to recover 3D-digital elevation model. Detailed review of for OPL corridors monitoring technologies with pros and cons of each technology is given in [1].

Maintaining of OPL corridors is a big issue in Russian electrical power sector. Several years this kind of activity was not sufficiently financed. At the same time the land-use rules was changed to increasing the cost of deforestation. The cost of construction a kilometer of OPL has become comparable to the cost of cutting down a hectare of forest [11]. According to the statistics, about $40 \%$ of OPL outages in Russia are caused by contiguity of OPL and vegetation [11]. Such outages occur due to influence of wind, ice accretion and forest fires. In addition to the concept of OPL corridor, which is an empty space around of OPL, an important concept is protection zone of OPL. A protection zone (Fig.1) is a space around OPL where all activities such as building and construction work, agriculture, etc. are limited to prevent electrocution and electromagnetic radiation hazard. Felling of trees in protection zone is also limited by safety restrictions. Distance $h$ from outermost to limits of protection zone depends on voltage rating. Distances $h$ for different voltage ratings are demonstrated in Table I. 
This paper is dedicated to analysis of protection zones, OPL corridors condition of several OPL $330 \mathrm{kV}$ and $110 \mathrm{kV}$ in Pskov region. Analysis is based on satellite sounding data and determination of normalized difference vegetation index (NDVI) inside protection zone.

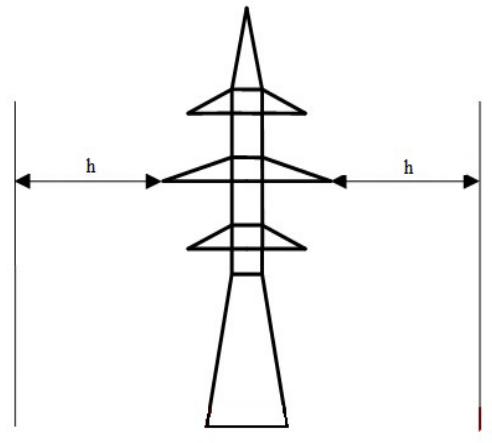

Fig. 1. Protection zone of overhead power line

TABLE I. DistANCES FROM OUTERMOST TO LIMITS OF PROTECTION ZONE

\begin{tabular}{|c|c|}
\hline Voltage rating, $\mathrm{kV}$ & $\begin{array}{c}\text { Distance } \\
\mathbf{h}, \mathbf{m}\end{array}$ \\
\hline Less than 20 & 10 \\
\hline 35 & 15 \\
\hline 110 & 20 \\
\hline 220 & 25 \\
\hline $330-500$ & 30 \\
\hline 750 & 40 \\
\hline 1150 & 55 \\
\hline
\end{tabular}

\section{Materials and Methods}

At the moment, the main method of obtaining information about protection zone of OPL in the Russian Federation is a visual inspection conducted by employees of power grid companies. This method has been used for a long time in the electric grid complex and is regulated by technical standards. Significant weakness of the method is the influence of human factor at the stage of collecting, processing and data retention, high labour intensity and considerable time costs, especially when examining hardto-reach areas of OPL.

In addition to the above methods of collecting information, another cluster of monitoring methods has been intensively formed over the last decades, associated with usage of various technologies of remote sensing data. These methods have high performance, an extensive area of geoinformation collection, provide correct spatial data about parameters of OPL state in digital form and allow to exclude subjectivity at the stage of data collection.

The overgrowing of OPL protection zones with woody vegetation is a significant problem, since the presence of potentially dangerous objects in this area can cause disruptions in the power transmission or even lead to a break in the power lines. The Russian Federation has a huge territory and monitoring the overgrowing of protection zones always is fraught with great difficulties. One of the possible solutions to this problem is the use of remote sensing data. It is less accurate compared with aerial photography in detail and accuracy, but it greatly exceeds in the space of the one-time coverage. Taking into account the capabilities of modern multispectral satellite sensors and the availability of open hubs of data, their use in conjunction with advanced GIS tools allow to identify "risk zones" in large areas in a very short time.

To assess the overgrowth of protection zones, one of the most common and theoretically based vegetation indices - the NDVI index, which is distinguished by a simple method of calculation and rather high accuracy were used. It applies makes it possible to assess the areas of vegetation to be cleared in the protection zone of OPL. In case of doubtful situations, it is possible to check the problematic areas using aerial photography or visual inspection, which in any case, significantly reduces work input.

All stages of data preparation and the creation of vector layers were performed in the QGIS 3.4.

To identify areas of overgrowing of overhead power lines in the territory of the Pskov region, model transmission lines with a voltage rating equal to 110 and $330 \mathrm{kV}$ with a total length of $543.64 \mathrm{~km}$ were selected (Fig. 2). Then, in accordance with the standards of protect zone width along all power lines, a buffer zones was created in the vector geo-processing module of the QGIS 3.4. The total area of the protection zone for the lines under study was 2665.11 ha.

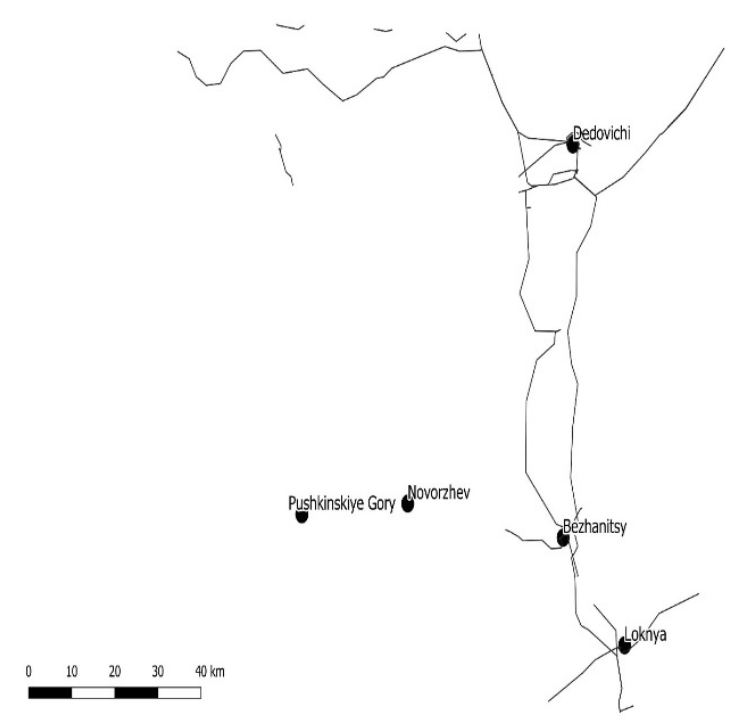

Fig. 2. Configuration of investigated $110 \mathrm{kV}$ and $330 \mathrm{kV}$ overhead power lines in the territory of the Pskov Region

Next, to identify the nature of vegetation from the website of the Copernicus Open Access Hub, a Sentinel-2 satellite image with a minimum cloudiness for June 2018 was obtained. NDVI index was calculated using the "raster calculator" tool in the QGIS program using the formula [12]with potentially important feedbacks to regional and global climate through altered carbon cycle and albedo dynamics. These feedback processes 
will be affected by vegetation changes, and feedback strengths will largely rely on the spatial extent and timing of vegetation change. Satellite remote sensing is widely used to monitor vegetation dynamics, and vegetation indices (VIs:

$$
N D V I=\frac{N I R-R E D}{N I R+R E D}
$$

where NIR is the reflection in the near infrared region of the spectrum; RED is reflection in the red region of the spectrum.

For the Sentinel-2 satellite, the near-infrared channel corresponds to band number 8 , and the red channel corresponds to band number 4 .

After calculating the NDVI index for the study area, the procedure for classifying the state of vegetation by ranges of the index value was performed. As a basic tool for decryption, the classification with training included in the SCP module (Semi-automated classification) was used. After selecting the most successful classification option, all images were converted to vector format and using the QGIS field calculator tool, areas of certain classes of NDVI values in hectares were calculated.

\section{Result And Discussion}

NDVI estimation is widely used for regional mapping, landscape analysis, resource evaluation, biosystem's area assessment. Such wide implementation can be explained by strong correlation between NDVI and ecosystem productivity. Different types of forests in central part of Russia (from boreal coniferous forests to mixed coniferous-broad leaved forests) identify as NDVI-values on the range between 0.65 and 0.80 [12]with potentially important feedbacks to regional and global climate through altered carbon cycle and albedo dynamics. These feedback processes will be affected by vegetation changes, and feedback strengths will largely rely on the spatial extent and timing of vegetation change. Satellite remote sensing is widely used to monitor vegetation dynamics, and vegetation indices (VIs. OPL corridor segments with such values of NDVI should be under the spotlight of electric grid company. It is important to note that NDVI first of all demonstrates intensity of photosynthesis on investigating area. LIDAR sensing as additional measure to assess forest height can help to determine risk of damage for OPL.

According to classification of NDVI ranges, we determined four main classes for our protection zones (Table II).

Classes of NDVI fOR PROTECTION ZONES

\begin{tabular}{|l|c|c|}
\hline \multicolumn{1}{|c|}{ Class of vegetation } & NDVI values & Area, hectares \\
\hline First class (dense vegetation) & $\begin{array}{c}\text { more than } \\
0.65\end{array}$ & 1012.18 \\
\hline Second class (sparse vegetation) & $0.375-0.60$ & 1224.78 \\
\hline Third class (meadows) & $\begin{array}{c}\text { less than } \\
0.375\end{array}$ & 358.8 \\
\hline Fouth class (open water surface) & 0.02 & 69.32 \\
\hline
\end{tabular}

Segments with the first class of vegetation pose significant risk for OPL due to possibility of crosswhipping with short circuit or wirebreak. Periodic field measurements of forest stand height and comparing them with results of NDVI estimation are necessary measure for elaboration and verification of vegetation classes. Systematic comparison will allow improve classification quality and reduce costs of monitoring.

Preliminary assessment of explored fenced off areas shows that $62 \%$ of it belong to non-first class. This fact means that $38 \%$ of explored territory has non-negligible risk of failure accident and need line clearance for maintaining safety and reliability of power supply. Despite that sparse vegetation does not pose such threat to OPL work as dense vegetation does, current Russian regulations prescribe to remove this type of vegetation too. Consequently, $84 \%$ of OPL corridors require clearance to one degree or another.

The disadvantages of presented satellite sounding data analysis include resolution limitation (OPL less than 110 $\mathrm{kV}$ due to smaller sizes and distances for corridors and finch off areas require aerial monitoring), necessity of result validation by other methods.

\section{CONCLUSIONS}

The method for protection zones and forest corridors of OPL monitoring based on satellite sounding data and NDVI estimation was described. It allows to increase the efficiency of corridor clearance activities compare to traditional visual inspection conducted by employees of power grid companies.

Case study with several OPL in Pskov region total length about $543 \mathrm{~km}$ was done. It showed that $84 \%$ of OPL protection zones has as dense or sparse vegetation and require clearance activities.

Further work will be focused on long-term dynamics of vegetation in protection zones and investigation of clearance activities influence on vegetation dynamics. It will help to improve OPL maintenance and to reduce its costs.

\section{REFERENCES}

[1] L. Matikainen et al., "Remote sensing methods for power line corridor surveys," ISPRS J. Photogramm. Remote Sens., vol. 119, pp. 10-31, 2016.

[2] T. Bretterklieber, M. Neumayer, M. Flatscher, A. Becke, and G. Brasseur, "Model Based Monitoring of Ice Accretion on Overhead Power Lines."

[3] I. Dominik and M. Iwaniec, "Low Frequency Damage Analysis of Electric Pylon Model by Fuzzy Logic Application,” vol. 32, no. 3, pp. 239-251, 2013.

[4] T. Yin, H. F. Lam, H. M. Chow, and H. P. Zhu, "Dynamic reduction-based structural damage detection of transmission tower utilizing ambient vibration data Dynamic reduction-based structural damage detection of transmission tower utilizing ambient vibration data," Eng. Struct., vol. 31, no. 9, pp. 2009-2019, 2009.

[5] I. Y. Shurrab, A. El-hag, K. Assaleh, and R. Ghunem, "Partial Discharge On-Line Monitoring of Outdoor Insulators," pp. 391-394, 2012.

[6] A. Banik, "Condition Monitoring of Overhead line Insulator By 
measuring Surface Leakage Current,” 2014.

[7] G. Ma, C. Li, S. Member, J. Jiang, and J. Liang, "A Passive Optical Fiber Anemometer for Wind Speed Measurement on High-Voltage Overhead Transmission Lines," vol. 61, no. 2, pp. 539-544, 2012.

[8] J. Bernardino, "Bird collisions with power lines : State of the art and priority areas for research Bird collisions with power lines : State of the art and priority areas for," Biol. Conserv., vol. 222, no. April, pp. 1-13, 2018

[9] C. E. Commission, "BIRD STRIKE INDICATOR FIELD DEPLOYMENT AT THE AUDUBON NATIONAL,” 2008.
[10] J. Ahmad, A. S. Malik, L. Xia, and N. Ashikin, "Vegetation encroachment monitoring for transmission lines right-of-ways: A survey," Electr. Power Syst. Res., vol. 95, pp. 339-352, 2013.

[11] Ю. Соколов, “Об уроках массовых нарушений на сетях электроснабжения регионов Российской Федерации в декабре 2010 - январе 2011 гг. , вызванные гололедноизморозевыми явлениями," Стратегия гражданской зашиты проблемы и исследования., vol. 2, по. 2, pp. 81-97, 2011.

[12] M. M. Loranty et al., "Vegetation indices do not capture forest cover variation in Upland Siberian larch forests," Remote Sens. vol. 10 , no. 11,2018 . 